\title{
Changes in Aflatoxin Standards: Implications for EU Border Controls of Nut Imports
}

\section{Ilbtissem Taghouti (1), Jose-Maria Garcia-Alvarez-Coque(2), Victor Martinez-Gomez (2) \\ (1) National research Institute of rural engineering, Water and Forests (INRGREF), Tunisia \\ (2) Polytechnic University of Valencia, Spain ibtissem.taghouti@gmail.com}

\section{Introduction}

$\checkmark$ Public concerns about food-related health risks and suitable sanitary standards have been rising in many regions, particularly in EU

$\checkmark$ Aflatoxin (AF) standards are a common reason for trade disagreement and import notifications in the RASFF (Rapid Alert System for Food and Feed)

$\checkmark$ Few empirical analyses have identified the influencing factors in implementing Non-Tariff Measures (NTMS), specifically a Sanitary and Phytosanitary (SPS) measure

$\checkmark$ This study examines the factors influencing border controls of AF, based on political economy considerations, in a highly problematic group of products : Nuts
$>$ Natural AF contamination of nuts is unavoidable, yet it poses a major challenge for nut safety and quality

- Contamination can occur at any stage of the value chain especially when storage and drying facilities are inappropriate $>\mathrm{AFs}$ affect 4.5 billion people worldwide, with chronic exposure leading to various forms of cancer and even death (US Centers for Disease Control and Prevention, 2004; Emmott, 2012)

$>$ The most toxic and common $\mathrm{AF}$ is $\mathrm{B} 1$ and affects generally groundnuts, Brazil nuts, pistachio and walnuts

AF contamination can directly increase the likelihood of rejection at the border and constrain nut exports

Aflatoxins and nuts in the EU

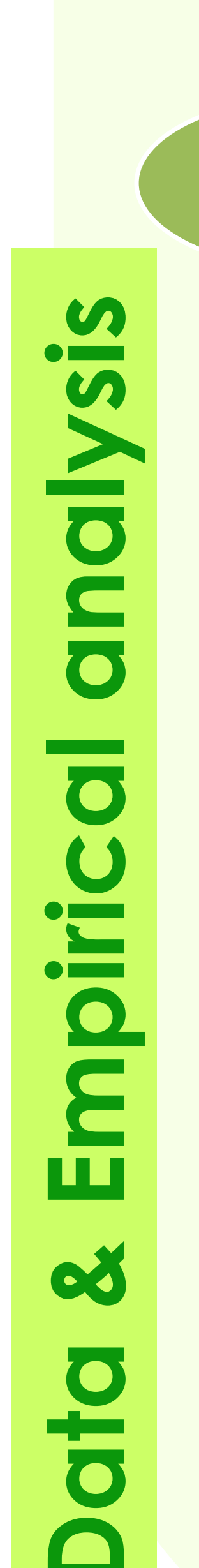

The EU member states had different $A F$ standards for foodstuffs imports

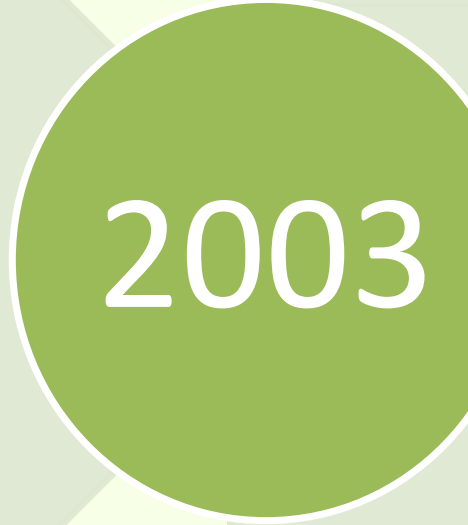
of origin and year

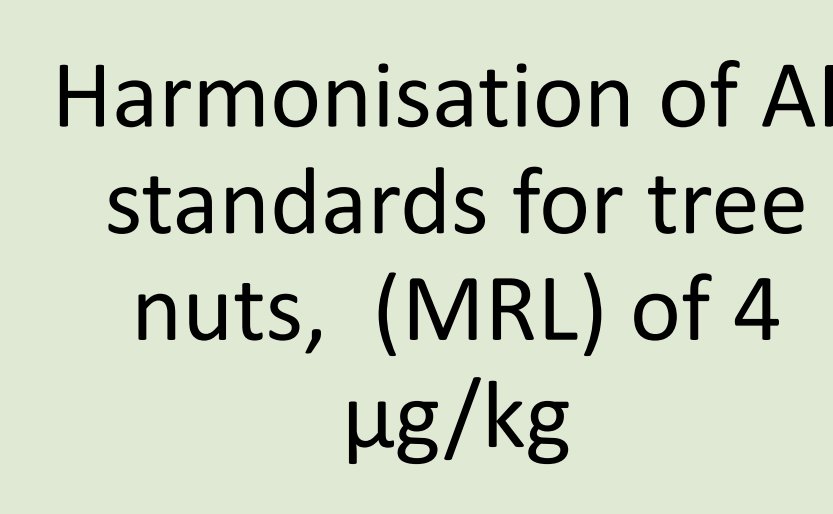
$\uparrow$

The EU's harmonised AF standards were more stringent than the Codex international standards

The model relies on RASFF notifications of AFS in nut imports $>$ The study examines 65 countries covering the period $1998-2015$

- The outcome variable provided the notification count by HS-6 code, country

> Trade data are used to account for annual bilateral trade volume

$>$ We focus on notifications emitted by only the 15 first EU member states to explore policy changes over an invariant number of EU member states

\section{Conceptual Framework}

$>$ The adapted framework to assess the trade impact of EU policy change includes the Exporting countries' capacity to meet EU standards \& Path dependence on previous decisions

Many efforts made by the public administration to optimise producer and consumer welfare through enforcing standards and border controls. The welfare objective $\mathrm{W}$ for the public administration affecting import controls is given by

$$
W=\varphi\left(\omega_{s}, \omega_{c}\right)
$$

Assuming that, $N_{i t,}$ is influenced by other political economy considerations : lobbying by producers ( $(\mathbb{S})$ and consumers ( $(\mathcal{C})$

$$
N_{i j t}=\phi\left(\ell_{s}, \ell_{c}, W\right)
$$

Previous research (Jouanjean et al., 2015; Tudela-Marco et al., 2016) found that more developed countries are less likely to fail a SPS control due to more developed pre-export facilities : measured by GDP per capita (pcGDP)

$>$ The model allows for dynamics aspect of RASFF notifications through identifying the effect of the history of member states' actions on present control measures

$>$ Current Notifications are likely affected by previous decisions

$>$ Product notifications for period (t) (HS-6 category) are path dependent on previous product notifications (Nijt-1) \& the

\begin{tabular}{|c|c|}
\hline Concept & Model variables \\
\hline Capacity of exporting countries & Development level (per capita GDP \\
\hline \multirow{3}{*}{ Consumer concerns ( $\mathbf{W c}$ and $\mathbf{l c}$ ) } & $\square$ Alerts (Ai) \\
\hline & Scientific awareness $(\mathbf{S})$ \\
\hline & Imports from each country of origin (Mij) \\
\hline \multirow{2}{*}{ Producer concerns ( Ws and Is ) } & Imports from each country of origin (Mij) \\
\hline & Q EU production of each nut (Qit) \\
\hline \multirow{2}{*}{ Path dependence effects } & Q Previous product notifications ( $(\mathrm{ijt}-\mathbf{1})$ \\
\hline & ב Country reputation (Njt-1) \\
\hline Policy substitution effects & Applied tariffs $\left(\mathbf{T}_{\mathbf{i}, \mathfrak{r})}\right.$ \\
\hline
\end{tabular}
reputation of the exporting country is related to total number of notifications received in previous periods $\left(N_{\mathrm{jt}-1}=\Sigma_{\mathrm{i}} N_{\mathrm{it}-1}\right)$

- NTMs depend on domestic consumer and producer concerns, $>$ The implementation of NTMs is affected by product and country reputation, indicating that past notifications on SPS non-compliance have a significant effect on current notifications

$>$ Events requiring rapid action like withdrawal from the market have a significant effect on the next year notifications

$>$ Results also support that NTMs may substitute tariffs in EU trade

- Further research is needed to analyse how changes in AF standards affect nut exports to the EU

$>$ Considering standard reforms as endogenous to the model would also provide an interesting research opportunity
The frequency of import controls decreased for various products from certain origins (Iranian pistachios and US almonds)

$\downarrow$

Modification of the harmonised MRLs for certain contaminants in foodstuffs keeping the same policy regarding Afs for nuts

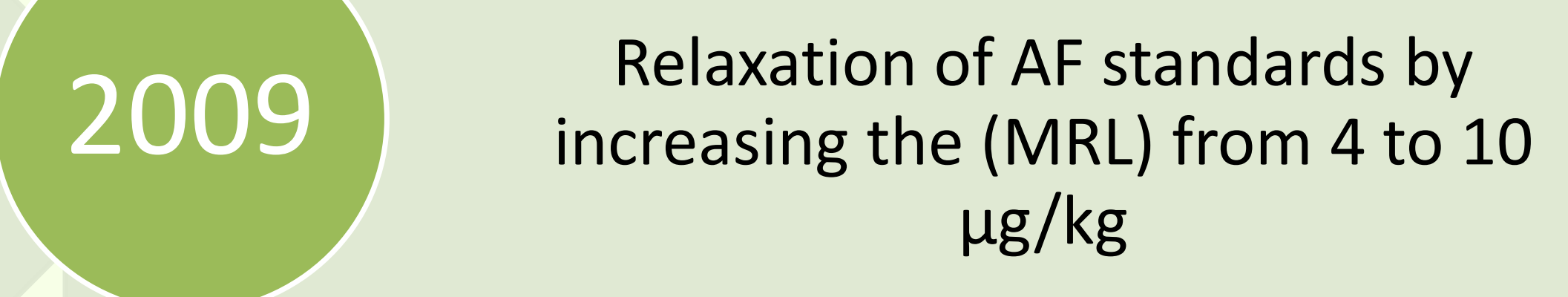

The EU aligned its MRLs with Codex MRLs for total AFs in

Ready-to-eat tree nuts : $10 \mu \mathrm{g} / \mathrm{kg}$

-Industrial processing tree nuts : $15 \mu \mathrm{g} / \mathrm{kg}$

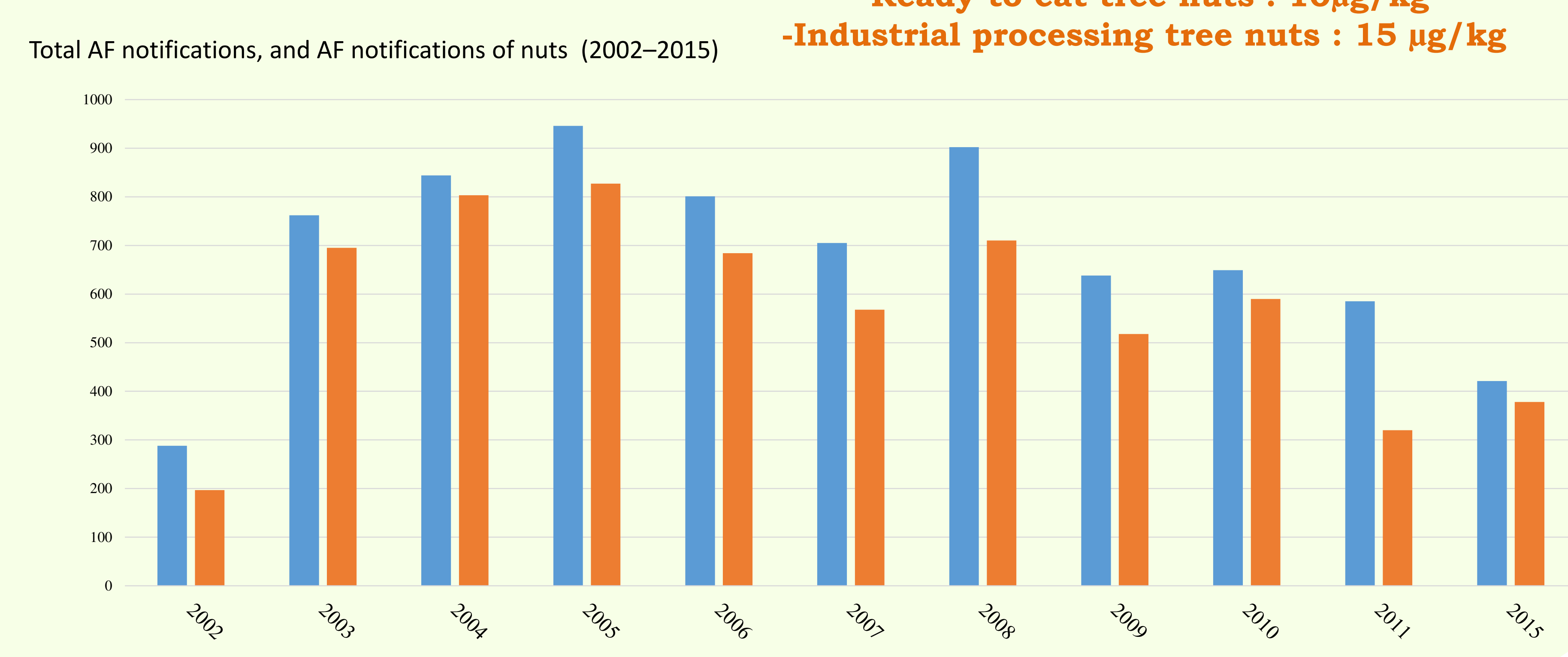

\begin{tabular}{|c|c|c|}
\hline ZINB & Negative binomial & Logit \\
\hline (Intercept) & $\mathbf{- 1 . 5 0 4 4 7}(0.12020)^{* * * * *}$ & $2.58930(0.10508)^{m+n+}$ \\
\hline $\mathrm{N}_{\mathrm{ijt}-1}$ & $\mathbf{0 . 0 2 1 2 5}(0.00180)^{* * * * *}$ & $-2.69360(0.12514)^{5+2 x}$ \\
\hline $\mathrm{N}_{\mathrm{jt}-1}$ & $-\mathbf{- 0 . 0 1 5 2 0}(0.00168)^{n+s z}$ & $-\mathbf{0 . 0 0 7 5 6}(0.00165)^{5=2 x}$ \\
\hline $\mathrm{A}_{\mathrm{ijt}-1}$ & 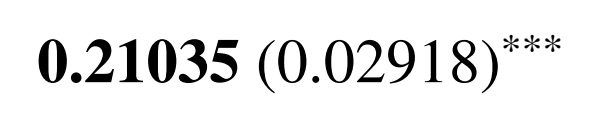 & $\mathbf{0 . 7 4 4 6 9}(0.31713)^{*}$ \\
\hline $\operatorname{Ln}\left(p c G D P_{t-1}\right)$ & $-\mathbf{0 . 0 0 0 2 9}(0.00012)^{*}$ & $0.00013(0.00011)$ \\
\hline $\operatorname{Ln}\left(\mathrm{M}_{\mathrm{ij}-1}\right)$ & $\mathbf{0 . 0 0 0 2 2}(0.00005)^{5 * w * x}$ & $-\mathbf{0 . 0 0 0 3 4}(0.00006)^{* * 3}$ \\
\hline $\operatorname{Ln}\left(Q_{\mathrm{it}-1}\right)$ & $\mathbf{0 . 0 0 4 8 8}(0.00215)^{*}$ & $0.01582(0.00255)^{n+w * w}$ \\
\hline $\operatorname{Ln}\left(S_{t}\right)$ & $\mathbf{0 . 0 4 9 0 0}(0.00834)^{p+n+w}$ & $\mathbf{0 . 0 1 8 9 2}(0.00766)^{*}$ \\
\hline $\mathrm{T}_{\mathrm{ijt}}$ & $-0.06204(0.01263)^{m+n}$ & \\
\hline Dummy 1998-2001 & $\mathbf{- 1 . 3 4 6 3 9}(0.08990)^{*+\infty x}$ & \\
\hline Nijt.1 & $\mathbf{0 . 1 1 4 8 8}(0.02097)^{* * *}$ & \\
\hline Njt.1 & $\mathbf{- 0 . 0 9 3 7 1}(0.01915)^{* * * * *}$ & \\
\hline$A_{i j t-1}$ & 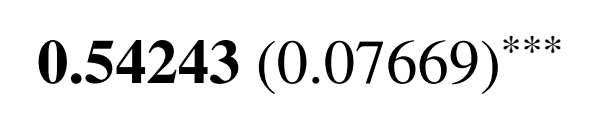 & \\
\hline Dummy 2010-2015 & $-\mathbf{0 . 8 2 2 7 9}(0.07627)^{*+\infty x}$ & \\
\hline Nijt.1 & $\mathbf{0 . 0 4 5 8 3}(0.00583)^{s+2 n e x}$ & \\
\hline Njt.1 & $-\mathbf{- 0 . 0 1 0 4 4}(0.00297)^{* * 3}$ & \\
\hline$A_{i j-1}$ & $\underline{\mathbf{- 0 . 1 8 4 2 2}}(0.05195)^{* * * * *}$ & \\
\hline
\end{tabular}

Findings and Discussion

Country fixed effects

Impact on notification count per period (percentage change)

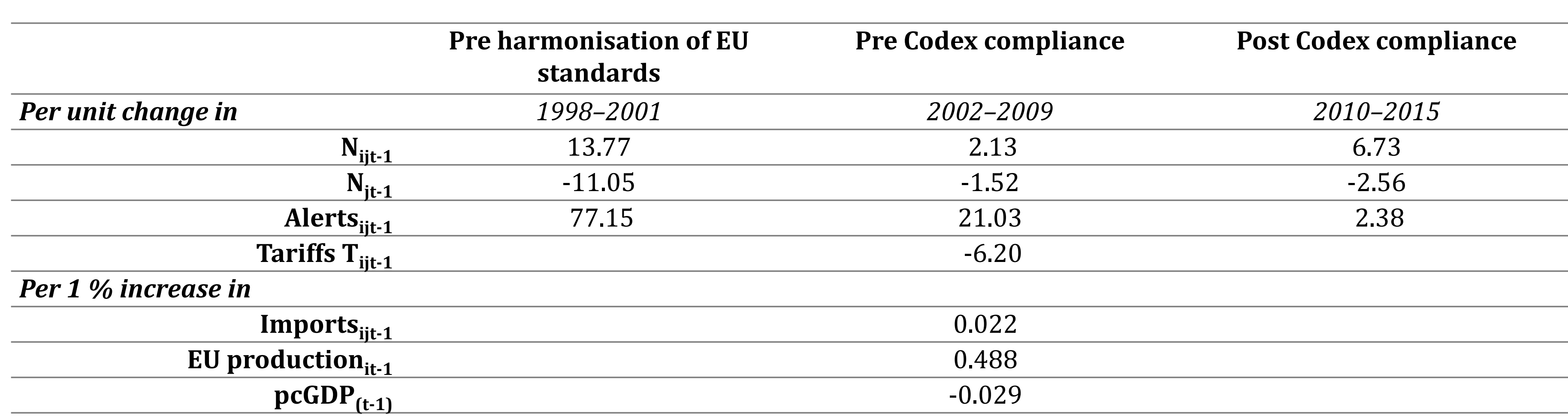

Scientific references,

Fixed effect period 4.90

\begin{tabular}{|c|c|c|c|c|}
\hline \multicolumn{2}{|c|}{$\begin{array}{l}\text { Average notification count } \\
\qquad(2013-2015)\end{array}$} & Non-Codex scenario & $\begin{array}{l}\text { Observed with } \\
\text { Codex }\end{array}$ & $\begin{array}{l}\text { \% Impact or } \\
\text { notification } \\
\text { count }\end{array}$ \\
\hline \multirow{10}{*}{ 吾 } & South Africa & 12 & 3 & -78 \\
\hline & United States & 67 & 26 & -62 \\
\hline & Argentina & 9 & 4 & -53 \\
\hline & India & 24 & 13 & -45 \\
\hline & Brazil & 19 & 11 & -41 \\
\hline & Nigeria & 2 & 1 & -40 \\
\hline & Iran & 51 & 35 & -32 \\
\hline & Egypt & 10 & 9 & -13 \\
\hline & Turkev & 55 & 49 & -11 \\
\hline & China & 56 & 54 & -3 \\
\hline \multirow{3}{*}{ 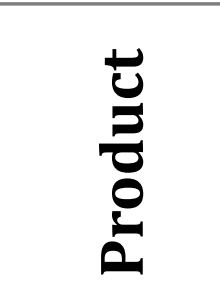 } & Pistachios & 98 & 51 & -48 \\
\hline & Peanut & 80 & 56 & -43 \\
\hline & Almond & 4 & 3 & -25 \\
\hline
\end{tabular}

Average notification count (2013-2015): non-Codex scenario

Notes: Source: Authors' calculations: ${ }^{* * *} p<0.001$, ** 